\title{
Negative Emotions and Defence Mechanisms in Obese People
}

\author{
Valeria Biasi ${ }^{1}$, Paolo Bonaiuto ${ }^{2}$ \\ ${ }^{1}$ Department of Education, "Roma Tre" University, Rome, Italy \\ ${ }^{2}$ Department of Psychology, "Sapienza" University of Rome, Rome, Italy \\ Email: valeria.biasi@romascuola.net, paolo.bonaiuto@uniroma1.it
}

Received 29 September 2014; revised 22 October 2014; accepted 12 November 2014

Copyright (C) 2014 by authors and Scientific Research Publishing Inc.

This work is licensed under the Creative Commons Attribution International License (CC BY). http://creativecommons.org/licenses/by/4.0/

(c) †) Open Access

\begin{abstract}
Previous investigations, using an effective non-invasive procedure of short-term experimental stress, proved that Obese vs. Normal Women develop about double the intensity of negative emotions (anxiety, anger, sadness) when under stress (Bonaiuto et al., 1993). A high production of negative emotions as a reaction to many everyday life stressors forces people to resort to psychological defense mechanisms. In the case of Obese Persons, these include oral regression ("neonatal regression") and somatization, together with repression and denial. The latter components are part of the so-called Lifestyle Defense Mechanisms, studied by Grossarth-Maticek (1980). In the rigorous revision and classification carried out by Spielberger (1988) and Spielberger \& Reheiser (2000, 2009), these factors were defined as "Need for Harmony" (N/H) and "Rationality/Emotional Defensiveness" (R/ED). In order to develop further appropriate indications, more than seven hundred Italian adults were examined by also recording the Body Mass Index (BMI) and using some evaluation tools, including the LDM Inventory. Significantly higher N/H scores were found in Obese Persons when compared with Overweight, Normal weight and Underweight ones. Other personological differences included significantly higher frequencies of the Type B Behaviour Pattern and higher average levels of Hyperphagic tendencies among the obese people. A development of this study involved more than one thousand participants and provided a confirmation of the influence of these defence mechanisms and personality structures as co-factors in determining obesity.
\end{abstract}

\section{Keywords}

Defence Mechanism, Negative Emotions, Obesity, Personality, Stress

\section{Introduction: Preliminary Investigation on Italian Adaptation of the Eating Habits Questionnaire, and the Correlations with Others Psychological Tools}

The problem of obesity, as a body anomaly linked to lifestyle and personality, has also become increasingly felt 
in Europe, raising concern within Clinical Psychology and Health Psychology and attracting the attention of the media.

In order to evaluate tendencies towards hyperphagia, i.e. Overeating Behavior, and to pursue further research objectives, our research group considered useful an Italian translation and adaptation of the Eating Habits Questionnaire (EHQ), a 57-item self-report inventory devised by Coker \& Roger (1990).

For that specifical investigation, the data were collected from two thousand participants aged 19 to 60 years. They were University students, graduates or employees of several public or private administrations, both genders equally represented at each age level.

The Eating Habits Questionnaire and the Body Mass Index evaluation were applied, together with other tools: the Adult Adolescent Type A Behavior Scale (AATABS, by Wrzesniewski, Forgays, \& Bonaiuto, 1990), to assess levels of Achievement Motivation and the inclinations to Type A or Type B Behaviour Patterns; and the Lifestyle Defense Mechanisms (LDM) Inventory (by Spielberger \& Reheiser, 2000), to assess inclinations to the Need for Harmony (N/H), to the Rationality and Emotional Defensiveness (R/ED), and their components.

The Eating Habits Questionnaire is a self-report scale, including 57 items posed in a dichotomized (true/false) format. It is designed to discriminate between subjects with and without eating disorders and to identify people at risk for developing eating disorders. The EHQ is centered on three factors lebeled "Concerns with Weight and Deiting", "Restraint", and "Overeating".

The AATABS score is devoted to indentify the Type A personality, that is a composite of characteristics including competitiveness, hurry, impatience, easy provoked hostility, need for control and, at a deeper level, an obscure need for compensating psychological insecurity, plus a more clear tendency to denial body impairment and, eventually, negative emotions. All these characteristics seem supported mostly by the strong level of achievement motivation, which is responsible for the arousing of the other typical features when facing unespected obstacles and frustrations in the attempt to reach the goals. At the contrary, Type B individual is described as relaxed, confident, unhurried, less easily provoked to anger, smooth modulation in speach and gestures, open to the broad richness of experience, but generally submissive, acquiescent and self-punitive.

The AATABS Scale shows 28 items each arranged on a five-point Likert scale, allowing a total score from 28 points (minimum) to 140 points (maximum), the individual average score is about 85, with standard deviation about 15. Type A Subjects are defined by more than one standard deviation (100 or more) above the mean.

Related to the EHQ data, a three-factor terminal solution was obtained by means of an Oblimin oblique rotation, using a criterion of 0.30 . All the 57 items loaded significantly on the three factors, and internal consistency was assessed according to Kuder \& Richardson, with a value of 0.78. The total EHQ Score turned out to be significantly correlated to the Body Mass Index $\left(\mathrm{r}_{754}=0.33, p<0.01\right)$. Each factor registered a positive correlation with this somatic indicator.

Moreover, the Body Mass Index was found to be higher among "Type Bs" than "Type As" (according to the AATAB Scale).

The same somatic indicator also positively correlated with the Need for Harmony $\left(\mathrm{r}_{754}=0.13 ; p<0.001\right)$ and with the Rationality/Emotional Defensiveness $\left(\mathrm{r}_{754}=0.12 ; p<0.01\right)$.

Defensive coping was assessed by the Lifestyle Defense Mechanism Inventory (LDM). This Questionnaire is based on two scales: the Need for Harmony $(\mathrm{N} / \mathrm{H})$ and the Rationality/Emotional Defensiveness (R/ED) scale consists of 12 items each

The LDM Inventory consists of two separate Scales, each of which includes two subscales. The first Scale, named "Need for Harmony" (NH), includes twelve items and is on turn divided into two Subscales: "Self-Sacrifice" (SS) and "Harmonious Relations" (HR): these components are focused on the efforts to achieve and mantain harmonious relationships with family and friends.

The second Scale, named "Rationality/Emotional Defensiveness" (R/ED) includes other twelve items and is the sum of two Subscales: "Rationality" (RAT) and "Emotional Defensiveness" (EmD). These components are focused on the frequency that a person engages in rational, anti-emotional thought processes and behaviors (Spielberger, 1988; Spielberger \& Reheiser, 2000).

Rating is based on a 4-point frequency scale, ranging from (1) "almost never" to (4) "almost always". Items are summed to give a range of 12 to 48 , where 48 indicates excessive use of unconscious defensiveness (i.e., repression and denial). For its development, the Rationality/Anti-emotionality questionnaire was used, which proved to be a reliable predictor of cardiovascular disease and cancer.

The LDM inventory in total has been administered to several populations and cultures and found to possess 
satisfactory psychometric properties.

\section{Hypersensitivity of Obese People to Stressors}

The Among the applications, our research group evaluated the behavior of young Obese Women who had marked tendencies towards Hyperphagia (i.e. Overeating Behavior), assessed with the above-mentioned Eating Habits Questionnaire (EHQ), properly translated and adapted in Italy.

Among the first outcomes of these data, collected in Rome, the Obese and Hyperphagic participants were found to be hypersensitive when subjected to a short-term experimental stress treatment.

The technique we used was the "Drawing of Stress", which consists of the recollected and drawn representations of real past personal stressful experiences (Biasi \& Bonaiuto, 1997). The stress treatment and drawing session lasted 15 minutes.

The participants were preliminary divided into two groups:

1) A first group of subjects with very high "Hyperphagia" scores in the EHQ, plus an Obese build (above 30 points of Body Mass Index, BMI);

2) A second group of participants with normal "Hyperphagia" scores in the EHQ, plus a Normal build (between 19 and 24 points of BMI).

Self Appraisal Scales were applied before and after the 15-minute stress treatment, in order to assess changes in emotions, feelings and motivations.

In the first group, with stress there was a remarkable activation of negative emotions (anxiety, anger, sadness, etc.), double the intensity of that shown by the normal participants (Figure 1). Differences reach statistical significance using Student's t test ( $\mathrm{A}=$ Anxiety: $\mathrm{t}_{26}=1.77 ; p<0.05$. $\mathrm{B}=$ Anger: $\mathrm{t}_{26}=1.71 ; p<0.05$. $\mathrm{C}=$ Sadness: $\mathrm{t}_{26}=2.14 ; p<0.03$ ).

Moreover, as a manifestation of psychological defense mechanism under stress conditions, there was the triggering of strongly regressive desires within the sphere of nutrition motivation (a so-called "neonatal regression", with increased yearnings for sweets, coffee, sleep, evacuation and inhaling; Figure 2). In detail, in stressed obese people there is an elective increase in a characteristic set of components of the motivation toward nutrition, measured by singe items: the desire for sweets $(\mathrm{S})$; the desire for coffee (C); the need for air (i.e. the impression of breathing difficulty and a feeling of suffocation (A); the desire for sleep and needs (R) connected with evacuation (E). The greatest differences between the two groups reach significance levels (Sleep: $\mathrm{t}_{26}=3.46 ; p<0.001$. Evacuation: $\left.\mathrm{t}_{26}=1.93 ; p<0.05\right)$.

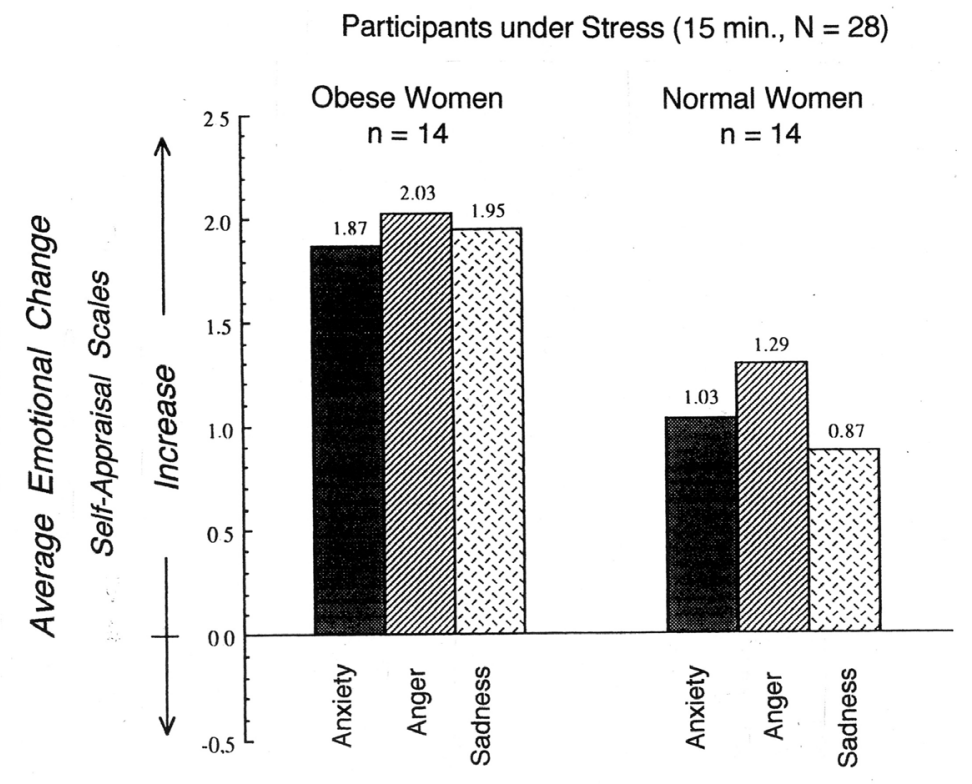

Figure 1. Average emotional changes in obese vs. normal women under stress (Bonaiuto, Biasi, Bonaiuto, \& Bartoli, 1993). 


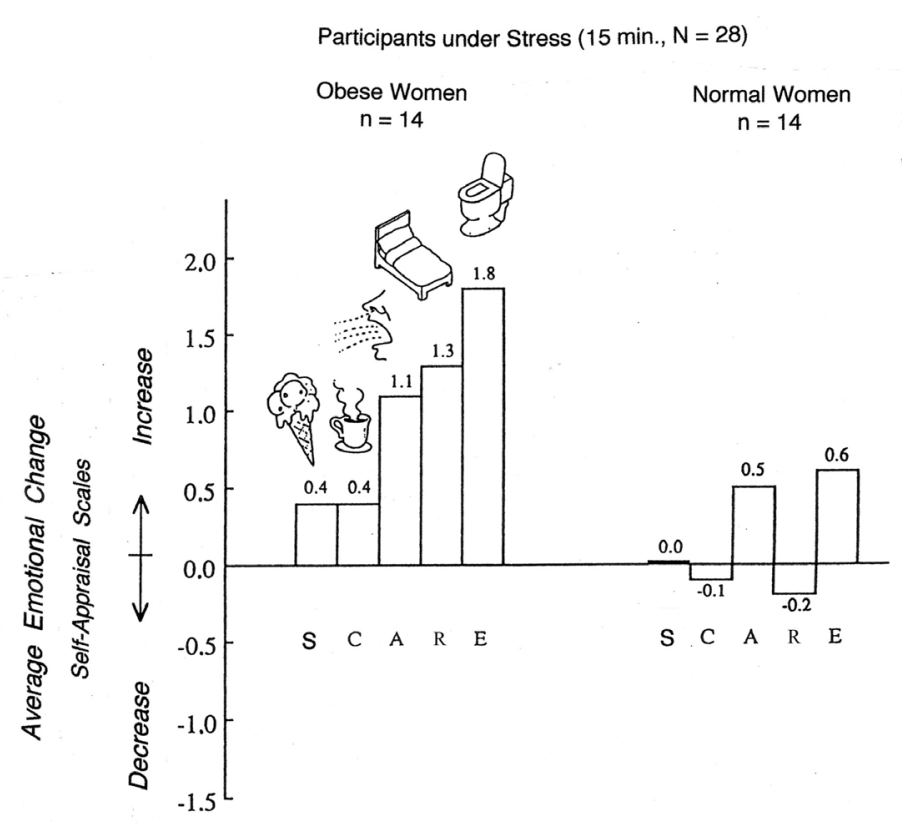

Figure 2. Average changes in nutritional wishes in obese vs. normal women under stress (Bonaiuto, Biasi, Bonaiuto, \& Bartoli, 1993).

Through infant observation, it has been know for some time that the attraction toward sweet tastes, linked to sucking and protective maternal figure, escape in sleep, hypomotility, the need for air, ease of evacuation, and distinct libidinal investment in the bodily functions listed above, are typical of the early phases of life.

Thus, we can speak primarly of regression of the obese individual under stress toward the so-called "oral phase" of personality development, almost wishing to return to a neonatal position.

More general effects of the clear increase in anxiety are linked with this form of regression: when anxiety is very intense, it can create an impression of breathing difficulty, a tendency toward evacuation and motor inhibition. Indeed, data show that the need for body movement decreases under stress in the obese person, whereas normally it increases (Figure 3; Bonaiuto, Biasi, Bonaiuto, \& Bartoli, 1993). The difference between the two groups is significant $\left(\mathrm{t}_{26}=1.99 ; p<0.03\right)$.

On the other side, the tendency to activate defence mechanisms (such as regression) may increase when the anxiety level surpasses certain limits (Freud, 1915-1917; Freud, 1936). It is well known that anger, especially in our culture, leads to further conflicts and thus, new anxiety. Also do to this, a part of anger and aggressiveness can be redirected toward self-punishment, raising the sadness level, also giving rise to an attitude oriented to denial and self-sacrifice, as described in next paragraph.

\section{Personality Differences Detected by Lifestyle Defence Mechanisms and AATAB Scale in Case of Eating Disorders}

We should consider that a higher production of negative emotions as a reaction to the many everyday life stressors forces people to resort to psychological defense mechanisms. In the case of Obese Persons, these include oral regression ("neonatal" regression) and somatization, as well as repression and denial of the negative emotions. The latter components are part of the so-called Lifestyle Defense Mechanisms, studied by Grossarth-Maticek (1980; see also Grossarth-Maticek \& Eysenck, 1990). In the rigorous revision and classification carried out by Spielberger (1988); and by Spielberger \& Reheiser (2000), these factors were defined as "Need for Harmony" (N/H: the tendency to avoid interpersonal conflicts even at the cost of self-sacrifice; Figure 4) and "Rationality/Emotional Defensiveness" (R/ED). Both these mechanisms can be measured through the Lifestyle Defense Mechanisms (LDM) Inventory, a 24-item and four sub-scale questionnaire, recently translated and adapted in Italy by Comunian, Biasi, Giannini \& Bonaiuto (2003, 2004, 2005).

In order to develop the above-mentioned indications and hypotheses, more than seven hundred adult Italians 
Participants under Stress (15 min., $\mathrm{N}=28$ )

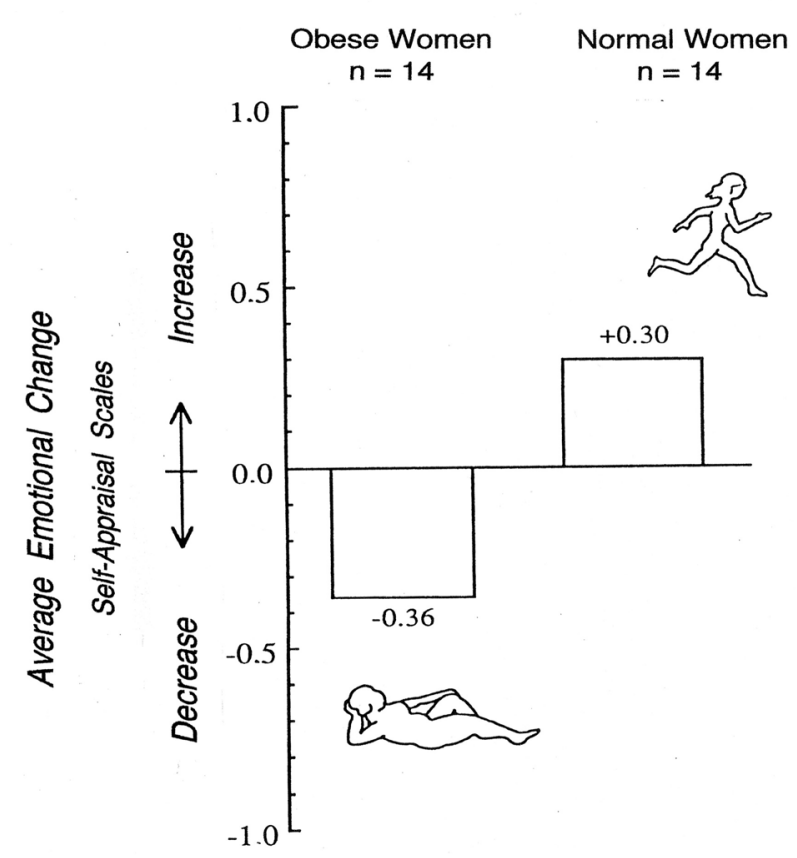

Figure 3. Average changes in body movement wishes in obese vs. normal women under stress (Bonaiuto, Biasi, Bonaiuto, \& Bartoli, 1993).

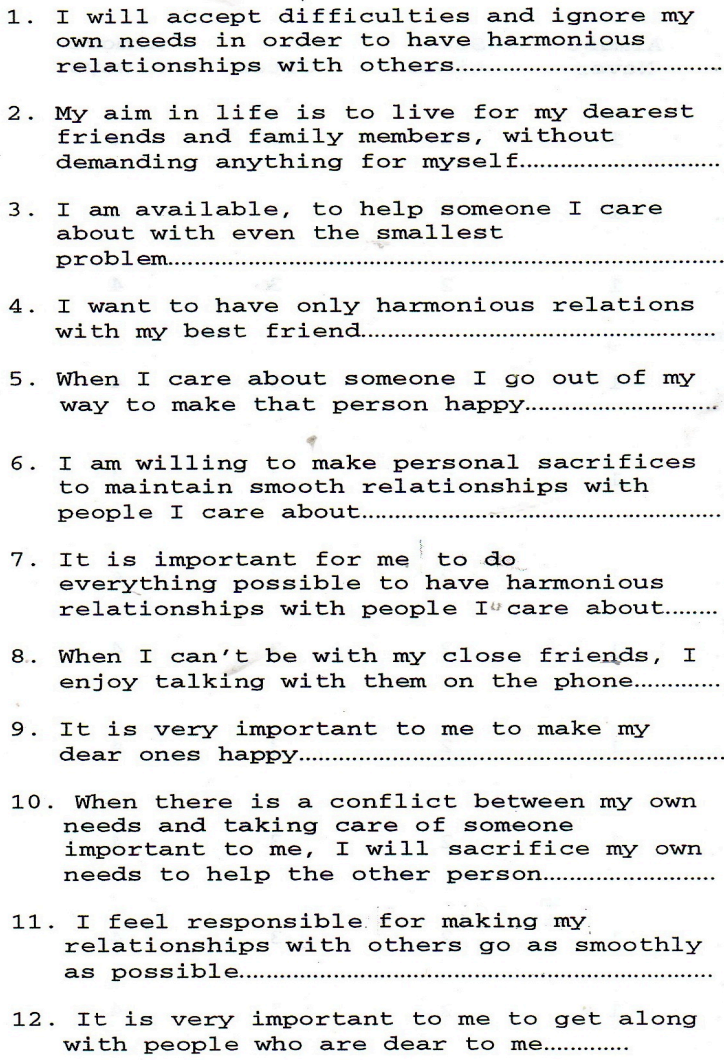

6. I am willing to make personal sacrifices to maintain smooth relationships with people I care about.

7. It is important for me to do everything possible to have harmonious relationships with people I care about........

8. When I can't be with my close friends, I enjoy talking with them on the phone.............

9. It is very important to me to make my dear ones happy.

10. When there is a conflict between my own needs and taking care of someone important to me. I will sacrifice my own inportant to me, I will sa

11. I feel responsible for making my relationships with others go as smoothly as possible.

12. It is very important to me to get along with people who are dear to me.............

Figure 4. Items of "need for harmony $(\mathrm{N} / \mathrm{H})$ scale" of the LDM inventory. 
were examined, by also recording the Body Mass Index (BMI) and using both the LDM Inventory and the AATAB Scale.

Methodological precautions made it necessary to equalise some variables when comparing the four experimental groups, made up of Obese, the Overweight, the Normal weight, and the Underweight participants.

Both genders were equally represented in each sub-group, and the average age was maintained constant.

To obtain this distribution, the overall number of experimental subjects was restricted in a previous study, by Biasi, Montemurro, Baralla, Bonaiuto and Bonaiuto (2007), to 796 participants, selected from the original larger group of over 1000 subjects.

After this necessary selection, the experimental subjects had the following distribution: Obese Persons $n=40$; Overweight Persons $n=222$, Normal weight Persons $n=500$; Underweight Persons $n=34$.

Statistical calculations confirmed that significantly higher scores of Need for Harmony $(\mathrm{N} / \mathrm{H})$ as a Defence Mechanism, are found in Obese Persons, when compared with Overweight, Normal weight and Underweight ones (Figure 5). At the analysis of variance test, this general effect turned out significant: $F(3,788)=2.66 ; p<$ 0.02 .

As regards the internal components (sub-scales) of the Need for Harmony scale, the tendency to Self Sacrifice (SS) was significantly lower in the Underweight participants with respect to the other groups, with a statistical significance of the differences and a main effect characterised by $F(3,788)=4.450 ; p<0.01$ (Figure 6).

The Rationality and Emotional Defensiveness scores look similar in the various groups, with no significant differences.

Other personological differences include significantly higher frequencies of the Type B Behaviour Pattern



Figure 5. LDM inventory and obesity: need for harmony (N/H) scale. $\mathrm{n}=796$; $\mathrm{F}(3,788)=2.66 ; p<0.02$.

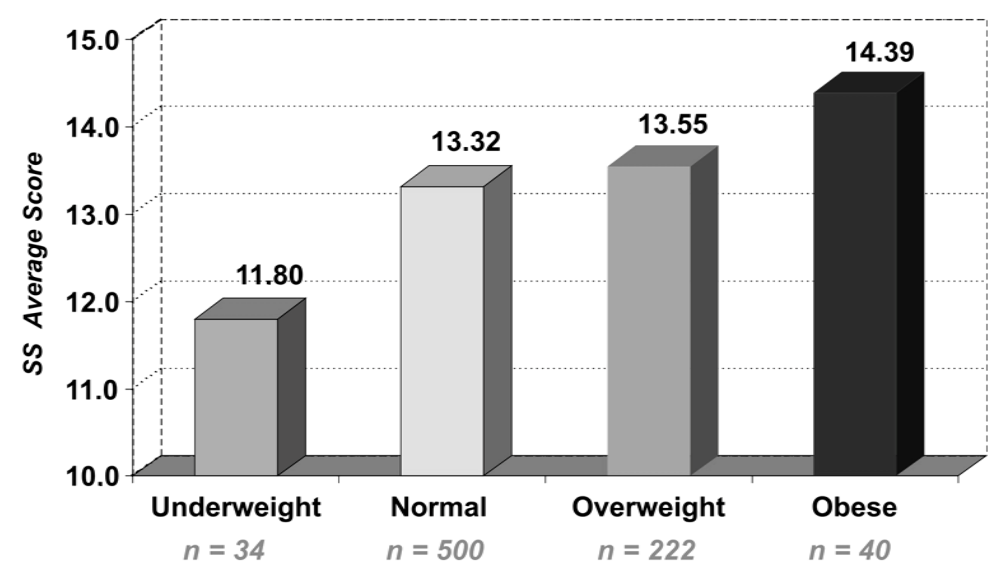

Figure 6. LDM inventory and obesity: self-sacrifice (SS) sub-scale. $\mathrm{n}=796$; $\mathrm{F}(3,788)=4.45 ; p<0.01$. 
among the Obese and Overweight groups of participants; and, coherently, lower values of Achievement Motivation (Type A score) in the Obese group (Figure 7); with a main effect characterised by $F(3,788)=3.605 ; p<$ 0.02 .

The results of applying the Eating Habits Questionnaire see the Overeating Behavior component (Hyperfagie) particularly efficacious, and the main effect is characterised by $F(3,788)=20.5554 ; p<0.0001$ (Figure 8).

A development of this study involved more than one thousand participants and provided a confirmation of the influence of these defence mechanisms and personality structures as co-factors in determining obesity (Figures 9-12).

All this data increase the consistency of the effects produced by the defence mechanisms, that are linked to the personality structure, and that can be efficaciously interpreted on the basis of psychodynamic constructs.

\section{Conclusions}

Finally, our statistical results point to the need to equalise the BMI values in the various subgroups before making comparisons in research on participants with eating disorders.

Significantly higher Need for Harmony (N/H) and Self-Sacrifice (SS) scores were found in Obese Persons when compared with Overweight, Normal weight and Underweight ones.

Other personological differences included significantly higher frequencies of the Type B Behaviour Pattern and higher average levels of Hyperphagic tendencies among the Obese people.

According to psychodynamic interpretations, obese persons develop specific defence mechanism as regression

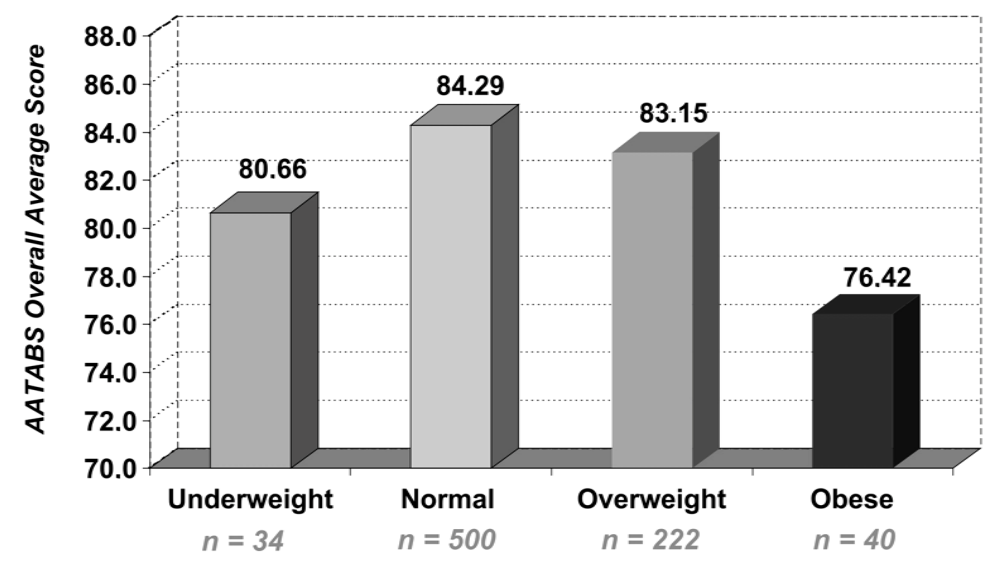

Figure 7. Achievement motivation scale (AATAB) and obesity. $\mathrm{n}=796$; F (3, 788) $=3.60 ; p<0.02$.

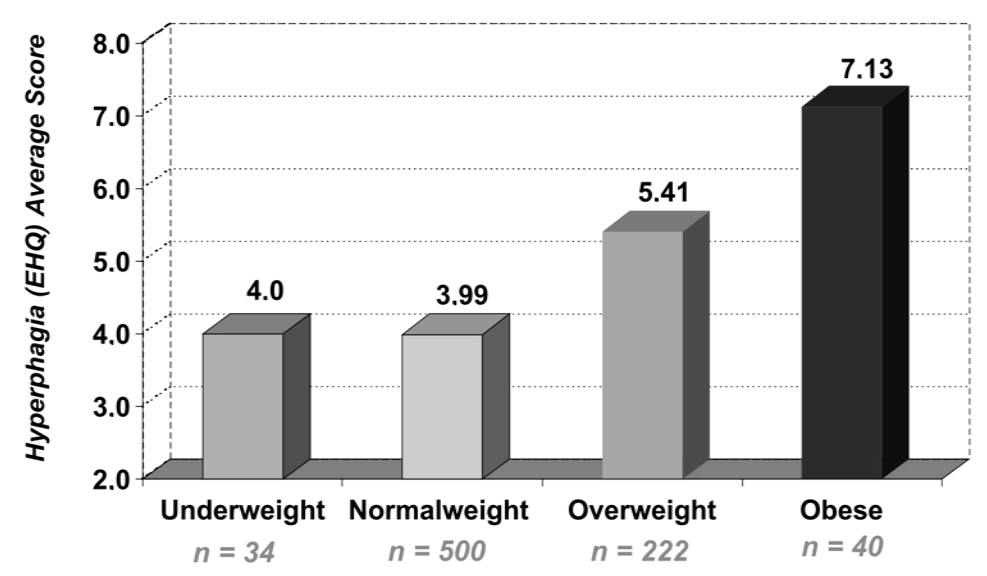

Figure 8. Eating habit questionnaire (EHQ), hyperphagia average score and obesity. $\mathrm{n}=796 ; \mathrm{F}(3,788)=20.555 ; p<0.0001$. 


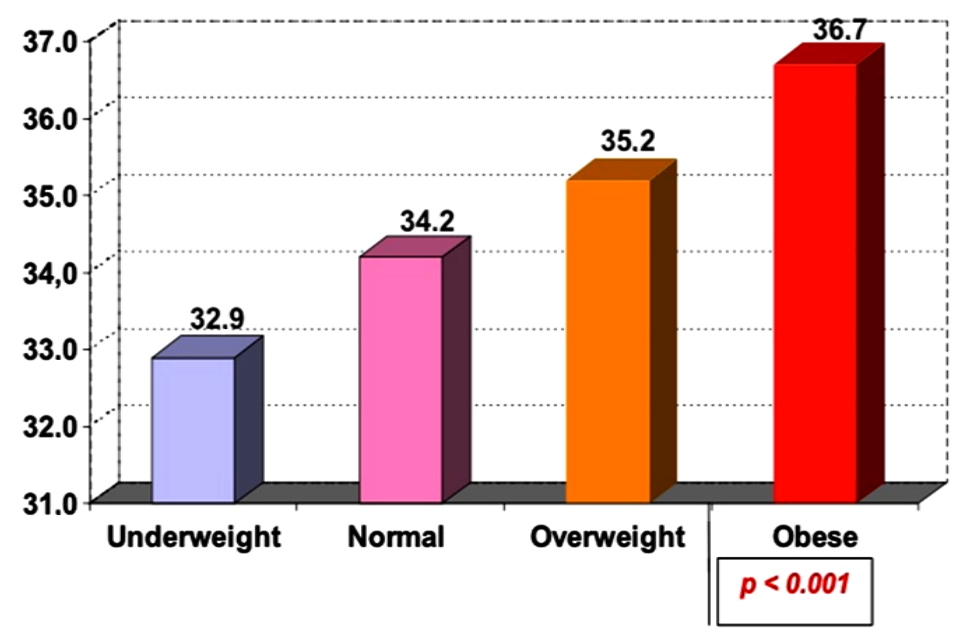

Figure 9. LDM inventory and obesity: Need for harmony $(\mathrm{N} / \mathrm{H})$ scale. $\mathrm{n}=$ 1008; F $(3,1004)=5.13 ; p<0.002$.

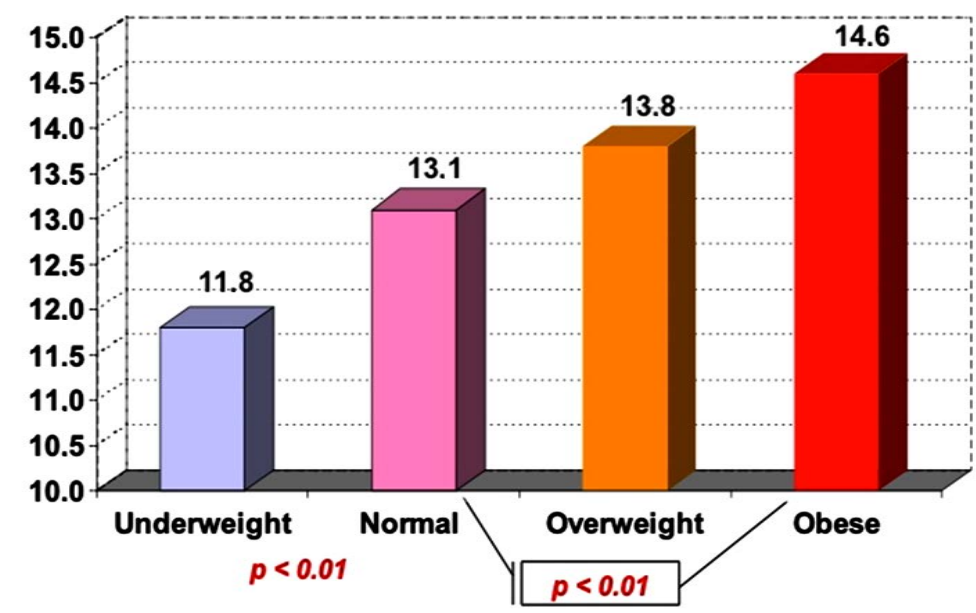

Figure 10. LDM inventory and obesity: self-sacrifice (SS) sub-scale. $\mathrm{n}=$ 1008; $\mathrm{F}(3,1004)=10.60 ; p<0.0001$.

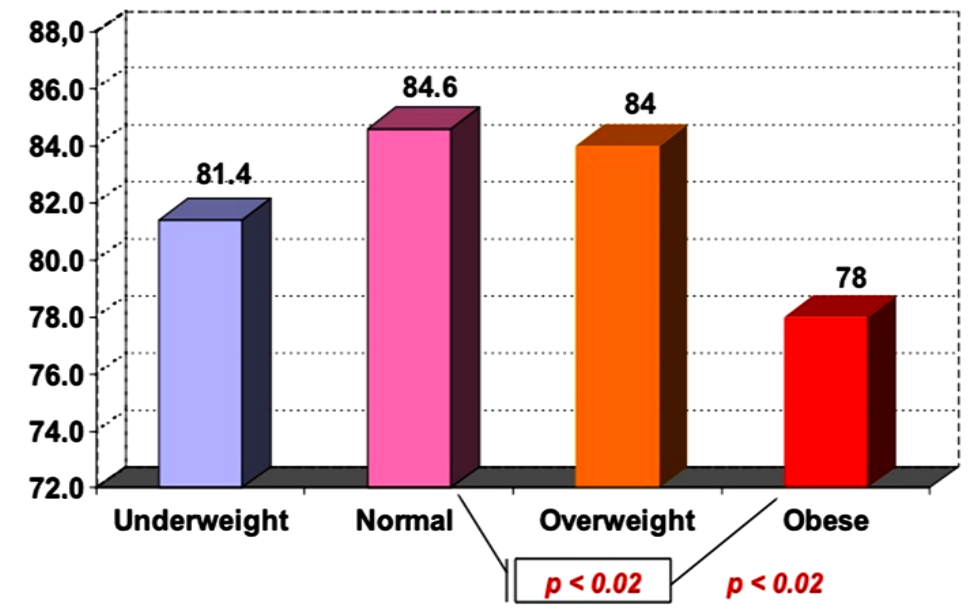

Figure 11. Achievement motivation scale (AATAB) and obesity. $\mathrm{n}=1008$; $\mathrm{F}$ $(3,1004)=3.95 ; p<0.01$. 




Figure 12. Eating habit questionnaire (EHQ), hyperphagia average score and obesity. $\mathrm{n}=1008 ; \mathrm{F}(3,1004)=16.35 ; p<0.0001$.

(particularly oral and neonatal regression, as indicated in paragraph 2), and especially Type B persons develop hypocondriasis, need for affiliation, passive-aggression and acting out, that are generally related to self-abuse behaviour. Note that obesity is one of the main effect of self-abuse behaviour. Our data show that obesity and Type B score are frequently correlated.

Moreover, Type B have a dependent personality, they need relationship that assures help and support; now we can better understand this kind of food dependency.

On the other hand, the personality structure of obese person is generally oriented to prevent or reduce interpersonal conflicts, even at the cost of denial and self-sacrifice, and the repression of negative emotions appears as a significant risk factor also for tumoural pathologies as detected in different international investigations.

It is known that in the past high levels of N/H and R/ED scores were found in Cancer Patients (Swan, Carmelli, Dame, Rosenman, \& Spielberger, 1992; Fernandez-Ballesteros, Zamarron, Ruiz, Sebastian, \& Spielberger, 1997; Bray, 2002; Calle, Rodriguez, Walzer-Trummond, \& Thun, 2003; and others).

It is also worth better exploring, for further developments, the relations between obesity and tumours, as well as the relations between the development of psychological defence mechanisms and the consequences produced on body health: such as immunodeficiency and hormonal disorders.

\section{References}

Biasi, V. \& Bonaiuto, P. (1997). Colour and the Experimental Representation of Stress and Comfort. In L. Sivik (Ed.), Colour \& Psychology (pp. 54-65). Stockholm: Scandinavian Colour Institute.

Biasi, V., Montemurro, M., Baralla, F., Bonaiuto, F., \& Bonaiuto, P. (2007). Lifestyle Defense Mechanisms and Related Traits in Obese and Overweight People. In A. L. Comunian, \& R. Roth (Eds.), International Perspectives in Psychology (pp. 310-321). Aachen: Shaker Verlag.

Bonaiuto, P., Biasi, V., Bonaiuto, F., \& Bartoli, G. (1992). Personality, Stress and Emotional/Cognitive Disorders. Paper Presented at the Sixth European Conference on Personality, Symposium on "Personality and Health", Gröningen.

Bonaiuto, P., Biasi, V., Bonaiuto, F., \& Bartoli, G. (1993). Riverberi emotivi del disegno di stress in persone obese. Rassegna di Psicologia, 10, 105-135.

Bray, G. A. (2002). The Underlying Basis for Obesity Relationship to Cancer. Paper Presented at the International Research Conference on Food, Nutrition and Cancer, Washington DC.

Calle, E. E., Rodriguez, C., Walzer-Trummond, K., \& Thun, M. J. (2003). Overweight, Obesity and Mortality from Cancer in Prospective Studied Cohort of U.S. Adults. The New England Journal of Medicine, 348, 1625-1638. http://dx.doi.org/10.1056/NEJMoa021423

Coker, S., \& Roger, D. (1990). The Construction and Preliminary Validation of Escale for Measuring Eating Disorder. Journal of Psychosomatic Research, 34, 223-231. http://dx.doi.org/10.1016/0022-3999(90)90056-A

Comunian, A. L., Biasi, V., Giannini, A. M., \& Bonaiuto, P. (2003). The Validity and Reliability of the Lifestyle Defense Mechanisms Inventory in Italy. Paper Presented at the 24th International STAR Conference, Lisbon. Abstract publ. in A. Baptista (Ed.), 24th International Conference Stress and Anxiety. Book of Abstracts (p. 51). Lisboa: Universidade 
Lusòfona de Umanidades e Tecnologias.

Comunian, A. L., Biasi, V., Giannini, A. M., \& Bonaiuto, P. (2004). Psychometric Properties of the Italian Lifestyle Defense Mechanisms Inventory. Paper presented at the 25th International STAR Conference, Amsterdam, 2004. Abstract publ. in J. Meijer, \& R. Oostdam (Eds), 25th Stress and Anxiety Research Society Conference. Book of Abstracts (p. 63). Amsterdam: SCO-Kohnstamm Instituut.

Comunian, A. L., Biasi, V., Giannini, A. M., \& Bonaiuto, P. (2005). The Italian Version of the Lifestyle Defense Mechanisms Inventory: A Replication of Item Equivalence with a Bilingual Sample. Paper presented at the 9th European Congress of Psychology, Granada.

Fernandez-Ballesteros, R., Zamarron, M.D., Ruiz, M.A., Sebastian, J., \& Spielberger, C.D. (1997). Assessing Emotional Expression: Spanish Adaptation of Rationality/Emotional Defensiveness Scale. Personality and Individual Differences, 22, 719-729.

Freud, A. (1936). Das Ich und die Abwehrme ccanismen. Wien: Internat. Psychoan. Verlag.

Freud, S. (1915-1917, 1924). Vorlesungen zur Einführung in die Psychoanalyse. Wien: Heller.

Kuder, G. F., \& Richardson, M. W. (1937). The Theory of Estimation of Test Reliability. Psychmetrika, 2, 151-160. http://dx.doi.org/10.1007/BF02288391

Spielberger, C. D. (1988). The Rationality/Emotional Defensivness (R/ED) Scale. Preliminare Test Manual. Tampa, FL: Center for Research in Behavioral Medicine and Health Psychology, University of South Florida.

Spielberger, C. D., \& Reheiser, E. C. (2000). Lifestyle Defense Mechanisms Inventory. Tampa, FL: Center for Research in Behavioral Medicine and Health Psychology, University of South Florida.

Spielberger, C. D., \& Reheiser, E. C. (2009). Assessment of Emotions: Anxiety, Anger, Depression, and Curiosity. Applied psychology: Health and Well-Being, 1, 271-302.

Swan, G. E., Carmelli, D., Dame, A., Rosenman, R. H., \& Spielberger, C. D. (1992). The Rationality/Emotional Defensiveness Scale-II. Convergent and Discriminant Correlational Analysis in Males and Females with and without Cancer. Journal of Psychosomatic Research, 36, 349-359.

Wrzesniewski, K., Forgays, D. G., \& Bonaiuto, P. (1990). Measurement of the Type A Behavior Pattern in Adolescents and Young Adults: Cross-Cultural Development of AATABS. Journal of Behavioral Medicine, 13, 111-135. http://dx.doi.org/10.1007/BF00844994

Wrzesniewski, K., Kirby Forgays, D., Bonaiuto, P., \& Giannini, A. M. (2002). Gender and Age Differences in CoronaryProne Behavior: A Cross-Cultural Study. In G. Weidner, M. S. Kopp, \& M. Kristenson (Eds.), Heart Disease: Environment, Stress and Gender (pp. 165-171). Amsterdam: IOS Press. 
Scientific Research Publishing (SCIRP) is one of the largest Open Access journal publishers. It is currently publishing more than 200 open access, online, peer-reviewed journals covering a wide range of academic disciplines. SCIRP serves the worldwide academic communities and contributes to the progress and application of science with its publication.

Other selected journals from SCIRP are listed as below. Submit your manuscript to us via either submit@scirp.org or Online Submission Portal.
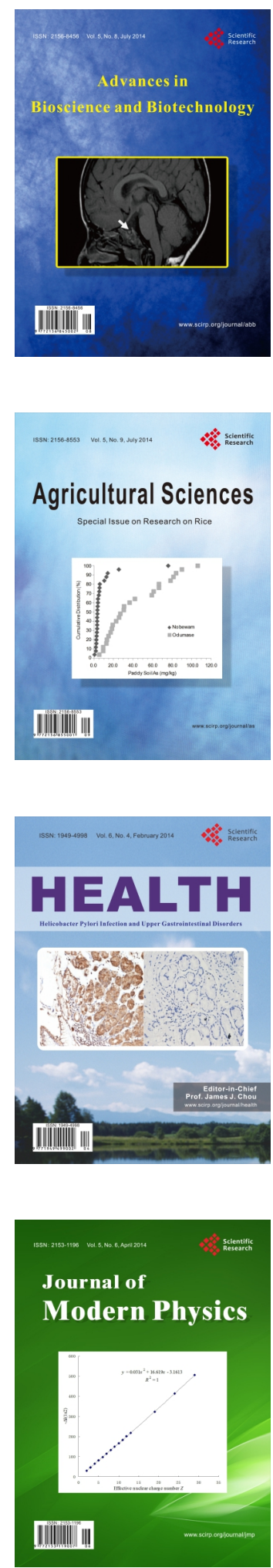
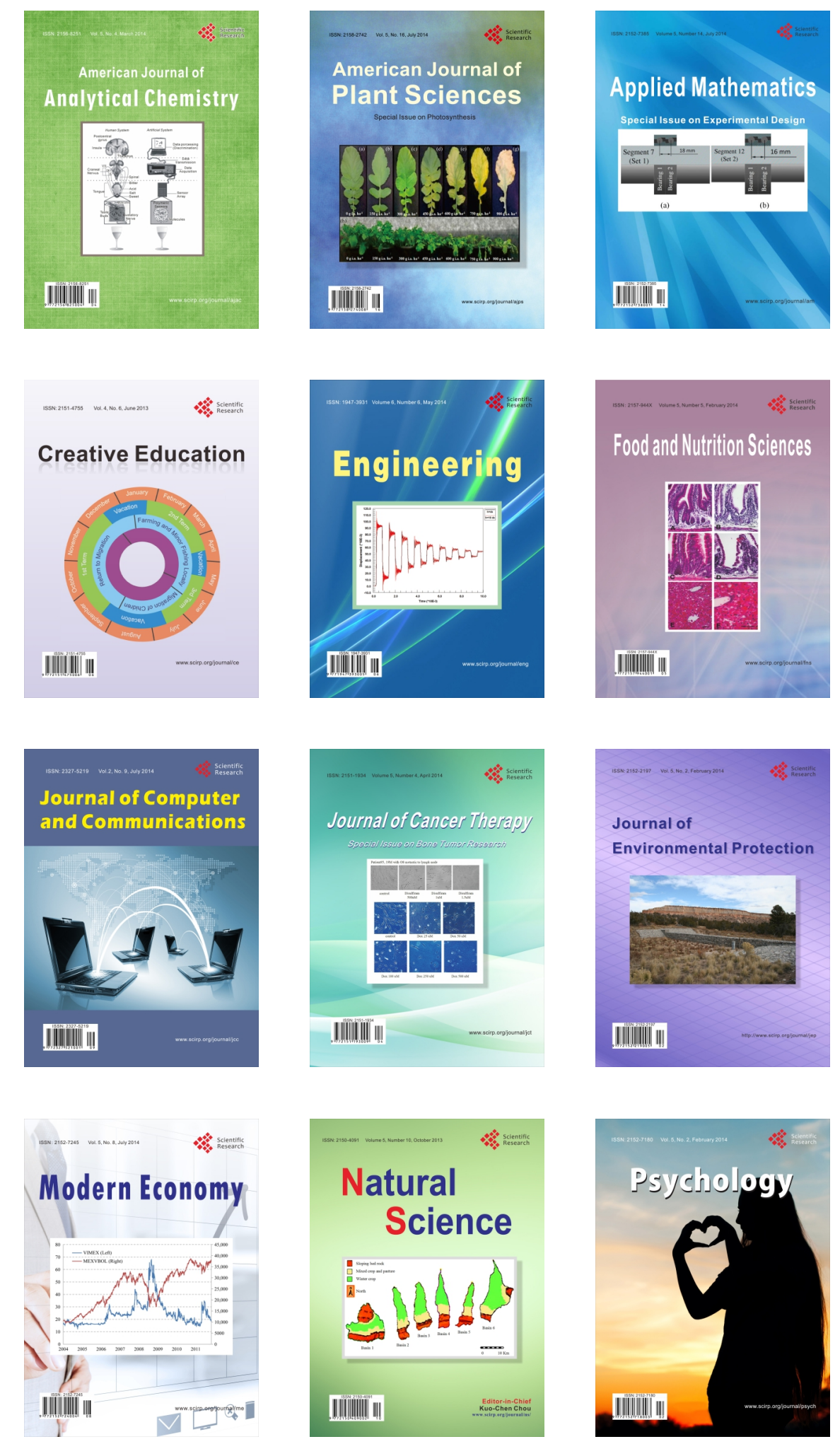